\title{
Dealing With Isolation Using Online Morning Huddles for University Lecturers During Physical Distancing by COVID-19: Field Notes
}

Yasuhiro Kotera, Pauline Green, Christine Rhodes, Alan Williams, James Chircop, Rachel Spink, Rebecca Rawson, and Uche Okere

University of Derby, Online Learning, Derby, United Kingdom

\begin{abstract}
Isolation can affect our well-being negatively. To prevent the spread of the infection COVID-19, many workers, including university lecturers, are required to work from home. In order to maintain high levels of well-being and team cohesion, academics at the University of Derby Online Learning initiated a virtual huddle to briefly socialise and check on their colleagues' well-being every morning. This piece of field notes reports the context (COVID-19 in the United Kingdom), the details of this morning socialization, the first-hand experience of attending this huddle, and possible applications. Perceived positive impacts of our huddles include better well-being, cultivating compassion in team culture, and enhanced team cohesion. These advantages can be also useful in student supervision, wider socialization with colleagues to counter the silo mentality, and other occupational sectors. Our field notes will be helpful for lecturers and other types of employees who work collaboratively yet in isolation during this uncertain and challenging time of crisis.
\end{abstract}

Keywords: isolation, well-being, team cohesion, COVID-19, crisis management 


\section{COVID-19 in the United Kingdom}

The coronavirus 2019 (COVID-19) pandemic originated in Wuhan, China (Hui et al., 2020), with the first case confirmed in December 2019 (Chen et al., 2020). As of June 4, 2020, there were 6.42 million cases with more than 382,800 deaths worldwide (European Centre for Disease Prevention and Control, 2020; World Health Organization, 2020). The United Kingdom (UK) has been as susceptible as any other country to the effects of COVID-19 because systems in society are integrated-a risk factor for infection (United Nations, 2019). Accordingly, in the UK and many other countries, what seem to be innocuous day-to-day activities such as going to work and socialising in person are now restricted (Coronavirus Act, 2020). Whilst the majority of the population will survive, the spread of COVID-19 is worrying because of the infectivity and recency of the disease; we do not fully understand the effects and therefore the human and economic costs of the virus (Coronavirus Act, 2020).

Since February 2020, many European countries and other countries in the world implemented measures of physical distancing and working from home to reduce new cases of infection and deaths, colloquially referred to as flattening the curve (Anderson, Heesterbeek, Klinkenberg, \& Hollingsworth, 2020; Mahase, 2020). Physical distancing is thought to be a key defence against the spread of the virus, therefore the UK government encouraged physical distancing and urged employers to facilitate working from home where possible, enacted in emergency legislation on March 23, 2020 (Cabinet Office, 2020; Coronavirus Act, 2020).

In order to comply with the government regulation, examples of good practice were reported, e.g., delivering teaching and holding meetings online instead of on campus, and changing arrangements for in-person summative assessments (Universities UK, 2020). At the University of Derby (UOD), teaching was suspended March 23 with all sites apart from Halls of Residence effectively closed on March 27, 2020, and all staff working from home (UOD, 2020).

The rapid move to working from home has forced individuals and organisations to learn how they can continue delivering education, requiring the implementation of multiple changes. At the University of Derby Online Learning (UDOL), while the curricula are offered almost solely online, onsite staff normally work together at the university due to various needs such as liaison with on-campus staff and engagement with external stakeholders. The majority of onsite academic staff at UDOL typically work three days at the university and two days at home. The three onsite days vary by portfolio (e.g., Monday, Tuesday, and Wednesday for our Inter-Professional portfolio). Accordingly, meetings and socialisation events are scheduled on those onsite days. This onsite-offsite work balance is similarly practiced by the on-campus academics who teach face-to-face. It is known that isolation can negatively affect our mental health (Holt-Lunstad, Smith, Baker, Harris, \& Stephenson, 2015) and academics' workplace team morale (Dolan, 2011). In order to mitigate such risks, academics at UDOL started short online gatherings every morning, which are being referred to as "morning huddles."

\section{Online Morning Huddles}

The morning huddles are scheduled from 9:00 to 9:15 a.m. daily. The online meeting link is established on Microsoft Teams (MS Teams), sent to 12 academics in the Inter-Professional portfolio (encompassing nursing, counselling, social work, and environmental studies), as recurring calendar 
invites with no set agenda. Many members log in before 9 a.m. to engage in casual conversation. The primary purpose of the huddle is to check everyone's well-being and to determine how they are maintaining their well-being in isolation. The conversations maintain a cordial and relaxed tone, and efforts are made to ensure that all colleagues get a chance to engage. In addition to video/audio interaction, a chat box is available to communicate with texts that provide additional information such as helpful links or, in some cases, little jokes which colleagues enjoy and respond to. Although scheduled for 15 minutes, conversations usually continue much longer. The huddle ends when we have exhausted all relevant issues and colleagues offer each other best wishes for the day.

\section{Perceived Positive Impacts of the Huddle}

Although it has been just two months, notable perceived positive impacts have been already reported by the attending staff, which can be summarised as (a) enhanced well-being, (b) cultivating compassion in team culture, and (c) team cohesion (Table 1). Staff feedback was collected in the huddles, and reviewed by each co-author independently, who then discussed and agreed with the final output.

Table 1

Characteristics of Online Morning Huddles

Perceived positive impacts $\quad$ Suggestions for possible applications

- Enhanced well-being (connectedness reduces loneliness).

- Cultivating compassion in team culture (placing well-being first).

- Enhanced team cohesion (daily checkin with team).
- Huddles with student groups (e.g., personal academic tutoring or supervision in the independent study).

- Huddles with a wider range of colleagues (e.g., academics in other disciplines, administrators, learning design or admission team).

- Workers in other sectors who normally work in the office but now need to isolate.

Note. Attended by 12 academics in the Inter-Professional portfolio (encompassing nursing, counselling, social work, and environmental studies).

Whereas general team meetings can provide opportunities to discuss ideas and make decisions (Kauffeld \& Lehman-Willenbrock, 2012), our morning huddles focus on caring for each other's wellbeing, which is the priority of this meeting (e.g., asking how they and their family are doing). By attending the huddle, we feel more compassionate and connected with the team (Dolan, 2011), which can counteract loneliness (a debilitating factor for well-being) in isolation to protect our well-being (Kotera, Green, \& Van Gordon, 2018; Victor et al., 2018).

At a team level in general, daily interactions in the huddles can enhance the compassionate culture and team cohesion echoing previous research into huddles in which workers report sincere care for and connection with colleagues (Chapman et al., 2020). We indeed perceived higher levels of caring for each other, and unity as a team at this uncertain time. Though often under-emphasised, these perceived positive impacts referring to connectedness are especially important to university lecturers as we are referred to as “connected professionals" (Oddone, Hughes, \& Lupton, 2019, p.109). 
Using these advantages, the huddles may be effective in other contexts. For example, periodic brief check-ins with supervised students, focusing on their well-being, may be useful in an independent study or a research project module. These types of check-ins may be more effective in distance education, as talking about non-academic issues may allow lecturers to see their supervisees more holistically (e.g., understanding their background). The caring and compassionate culture is important in many aspects of education, including the relationships with students (Claessens et al., 2017). The theory of human caring can support these ideas, because it asserts that humans are not objects, and thus can only be understood in the holistic perspective, and that caring transcends distance and physicality (Watson, 2008).

Additionally, huddles with a wider range of staff may be also useful, relating to enhanced team cohesion. The silo mentality is a problem in many higher education institutions (Reinholz \& Andrews, 2019), however, this easy-to-access meeting (just by clicking the link) may help different university colleagues mingle, leading to higher performance as a team. Likewise, huddles can be used by workers in different industries. For many office-based workers, home-based working as a result of COVID-19 is an enormous transition, demanding a great degree of adjustment (Stewart \& Menon, 2020). Regular, brief online catch ups can support their adjustment and foster their well-being.

\section{Discussion}

The present field notes report the utility of online morning huddles for university lecturers dealing with isolation under the COVID-19 pandemic. The perceived positive impacts of huddles include better wellbeing, cultivating a caring culture, and team cohesion, which suggest the usefulness of sharing this good practice with many other academics and workers in the world, who are in a similar situation. Particularly, well-being of faculty is often an under-recognised area of research (Ng, 2006), indicating the value of this piece of field notes.

One of the original values of the present field notes may be that while our experience supports the usefulness of occasional meetings among lecturers for socialisation purposes (Naidu, 2014), this paper reports that online huddles may be even more effective during an uncertain crisis such as the COVID19 pandemic. This relatively easy-to-do practice can be useful to an increasing number of institutions worldwide that have started online provision of courses, managing their diverse faculties (Gallagher \& Garrett, 2013). Previously, several studies have highlighted advantages and disadvantages of remote working for academics. Isolation is one of the salient difficulties they experience and feeling isolated can impact negatively on lecturers' performance (Kotera et al., 2019). Regular contacts with colleagues can enhance a sense of belonging, leading to better teaching performance and higher retention (Dolan, 2011). For lecturers and other types of workers who are in isolation during this crisis, the huddles may be one means to support their own and their team's well-being.

Whether or not you are a key worker, such as a nurse, doctor or delivery driver, the restrictions associated with the COVID-19 pandemic affect everyone. For university staff and those with office-based employment, working from home is viable, at least in the short term. John F. Kennedy noted how the word crisis was written in Japanese and Chinese using the characters that mean danger and opportunity (危機). We hope this crisis will turn from danger to opportunity by maintaining our wellbeing using practices such as the morning huddles. 


\section{References}

Anderson, R. M., Heesterbeek, H., Klinkenberg, D., \& Hollingsworth, T. D. (2020). How will countrybased mitigation measures influence the course of the COVID-19 epidemic? The Lancet,

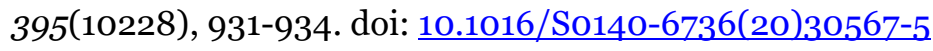

Cabinet Office. (2020). Staying at home and away from others (social distancing). Retrieved from https://www.gov.uk/government/publications/full-guidance-on-staying-at-home-and-awayfrom-others/full-guidance-on-staying-at-home-and-away-from-others

Chapman, L., Molloy, L., Wright, F., Oswald, C., Adnum, K., O’Brien, T., \& Mitchell, R. (2020). Implementation of situational awareness in the pediatric oncology setting. Does a 'huddle' work and is it sustainable? Journal of Pediatric Nursing, 50, 75-80.

Chen, N., Zhou, M., Dong, X., Qu, J., Gong, F., Han, Y., Qiu, Y., ... Zhang, L. (2020). Epidemiological and clinical characteristics of 99 cases of 2019 novel coronavirus pneumonia in Wuhan, China: A descriptive study. The Lancet, 395(10223), 507-513. doi: 10.1016/So1406736(20)30211-7

Claessens, L. C. A., van Tartwijk, J., van der Want, A. C., Pennings, H. J. M., Verloop, N., den Brok, P. J., \& Wubbels, T. (2017). Positive teacher-student relationships go beyond the classroom, problematic ones stay inside. The Journal of Educational Research, 110(5), 478-493. doi: $\underline{10.1080 / 00220671.2015 .1129595}$

Coronavirus Act. (2020). UK act of parliament. Retrieved from http://www.legislation.gov.uk/ukpga/2020/7/contents/enacted

Dolan, V. L. B. (2011). The isolation of online adjunct faculty and its impact on their performance. The International Review of Research in Open and Distributed Learning, 12(2), 62-77. doi: 10.19173/irrodl.v12i2.793

European Centre for Disease Prevention and Control. (2020). Situation update worldwide. Retrieved from https://www.ecdc.europa.eu/en/geographical-distribution-2019-ncov-cases

Gallagher, S., \& Garrett, G. (2013). Disruptive education: Technology-enabled universities. Sydney: United States Studies Centre at the University of Sydney. Retrieved from https://www.ussc.edu.au/analysis/disruptive-education-technology-enabled-universities

Holt-Lunstad, J., Smith, T. B., Baker, M., Harris, T., \& Stephenson, D. (2015). Loneliness and social isolation as risk factors for mortality: A meta-analytic review. Perspectives on Psychological Science, 1O(2), 227-237. doi: 10.1177/1745691614568352

Hui, D. S., I Azhar, E., Madani, T. A., Ntoumi, F., Kock, R., Dar, O., ... Zumla, A. (2020). The continuing 2019-nCoV epidemic threat of novel coronaviruses to global health-The latest 2019 novel coronavirus outbreak in Wuhan, China. International Journal of Infectious Diseases, 91, 264-266. doi: 10.1016/j.ijid.2020.01.009 
Kauffeld, S., \& Lehmann-Willenbrock, N. (2012). Meetings matter: Effects of team meetings on team and organizational success. Small Group Research, 43(2), 130-158. doi: 10.1177/1046496411429599.

Kotera, Y., Cockerill, V., Green, P., Hutchinson, L., Shaw, P., \& Bowskill, N. (2019). Towards another kind of borderlessness: Online students with disabilities. Distance Education, 4O(2), 170-186. doi: $\underline{10.1080 / 01587919.2019 .1600369}$

Kotera, Y., Green, P., \& Van Gordon, W. (2018) Mental well-being of caring profession students: Relationship with caregiver identity, self-compassion, and intrinsic motivation. Mindfulness and Compassion, 3(2), 7-30.

Mahase, E. (2020). Covid-19: UK starts social distancing after new model points to 260 ooo potential deaths. BMJ (Clinical Research Ed.), 368, m1089. doi: 10.1136/bmj.m1089

Naidu, S. (2014). Looking back, looking forward: The invention and reinvention of distance education. Distance Education, 35(3), 263-270. doi: 10.1080/01587919.2014.961671

Ng, C. F. (2006). Academics telecommuting in open and distance education universities: Issues, challenges and opportunities. The International Review of Research in Open and Distributed Learning, 7(2). doi: 10.19173/irrodl.v7i2.300

Reinholz, D. L., \& Andrews, T. C. (2019). Breaking down silos working meeting: An approach to fostering cross-disciplinary STEM-DBER collaborations through working meetings. CBE Life Sciences Education, 18(3). doi: 10.1187/cbe.19-03-0064

Stewart, K., \& Menon, A. (2020). COVID-19 pandemic: How to navigate the transition to remote work. World Economic Forum. Retrieved from https://www.weforum.org/agenda/2020/03/covid19-transition-to-remote-work/

Oddone, K., Hughes, H., \& Lupton, M. (2019). Teachers as connected professionals: A model to support professional learning through personal learning networks. The International Review of Research in Open and Distributed Learning, 20(3), 103-120. doi: 10.19173/irrodl.v20i4.4082

United Nations. (2019). World economic situations and prospects. Retrieved from https://www.un.org/development/desa/dpad/wpcontent/uploads/sites/45/WESP2019 BOOK-web.pdf

Universities UK. (2020). Actions being taken by universities in response to coronavirus. Retrieved from https://www.universitiesuk.ac.uk/news/Pages/Actions-being-taken-by-universities-inresponse-to-coronavirus-.aspx

University of Derby. (2020). Coronavirus. Retrieved from https://www.derby.ac.uk/coronavirus/

Victor, C., Mansfield, L., Kay, T., Daykin, N., Lane, J., Grigsby Duffy, L.... Meads, C. (2018). An overview of reviews: The effectiveness of interventions to address loneliness at all stages of 
the life-course. Retrieved from https://whatworkswellbeing.org/wpcontent/uploads/2020/01/Full-report-Tackling-loneliness-Oct-2018 0151580300.pdf

Watson, J. (2008). Nursing: The philosophy and science of caring. Boulder, CO: University Press of Colorado.

World Health Organization. (2020). Coronavirus disease (COVID-19) pandemic. Retrieved from https://www.who.int/emergencies/diseases/novel-coronavirus-2019

\section{Athabasca \\ University}

(c) 